\title{
Effects of Acute Administration of a Single Dose of Date Fruit Juice (Phoenix dactylifera) on the Cognitive and Mood Performance
}

\author{
Duaa Saleh Al-Tuwairki ${ }^{1}$
}

\begin{abstract}
The aim of this study was to investigate the possible cognitive or mood performance effects following the administration of a single dose of $250 \mathrm{ml}$ of the date's drink to healthy volunteers, using several cognitive computerized assessments. Results showed that the palm date fruit could modulate many aspects of mood performance in adults. In this study participants were more alert, calmer, and more content after taking date fruit juice. The main enhancement in cognitive tasks was noticed in the reaction time (msecs) on numerous memory tasks.
\end{abstract}

\section{INTRODUCTION}

The fruit of palm date (Phoenix dactylifera) is considered an essential component of the diet in many parts of the world, especially in the Middle East and North Africa. It was cultivated over 6000 years ago (Mustafa et al., 1983). Dates are usually consumed fresh at Rutab stage or people may prefer to leave dates to dry until the Tamr stage. However, dates at the Tamr stage contain 24.2\% moisture (Ahmed and Ahmed, 1995).

Adequate levels of vitamins and minerals are essential for the best possible performance of many psychological processes that have both direct and indirect effects on brain function. These processes include neurotransmitter synthesis, cerebral blood flow, receptor binding, energy metabolism, and membrane ion pump function (Haller, 2005; Huskissonet al., 2007).

Dates contain more than 15 minerals and vitamins which include good sources of potassium, calcium and iron; reasonable amounts of vitamins $\mathrm{A}, \mathrm{B}_{1}, \mathrm{~B}_{2}$ and niacin (nicotinic acid); with fair amounts of copper, magnesium, chlorine, sulphur, zinc, and phosphorous (Al-Shahib and Marshall, 2003). Moreover, palm palm date fruit contain antioxidant properties because of phenolic components such as tannins and flavones.

Date fruit is considered to contain a higher percentage of protein compared with other types of fruit. Whereas other fruits, such as apples, oranges, bananas and grapes contain respectively $0.3 \%, 0.7 \%$, $1.0 \%$, and $1.0 \%$ protein, but dates contain $2.3 \%$ protein (Alshowiman, 1998). More than 20 different amino acids have been found in dates and many of these are found solely in dates, (Alshowiman, 1998). Moreover, in a more recent study it has been demonstrated that a $100 \mathrm{~g}$ of dates can provide $50-100 \%$ of the recommended daily amount of fiber as well as other essential nutrients (Al-Shahib and Marshall, 2002).

Cognition is defined as higher level of mental processes within our heads, such as conscious thoughts and feelings, designing plans, having opinions and deciding what to say easily. However, cognitive processes usually refer to the mechanisms underlying such activities as perceiving and recognizing objects, attending to sounds, learning simple responses and memorizing lists of items (Ashcraft, 2002).

The hormone estrogen was first identified in the palm palm date (Phoenix dactylifera). It has been reported to have effects on improving cognition and delaying the progression of diseases (Doraiswamy et al., 1997).

Estrogens in nerve cells decrease the accumulation of amyloid beta protein (a protein consisting of amyloid peptides) which is a substance associated with Alzheimer's disease. Patients with Alzheimer's disease also have an abnormal deficiency in acetylcholine. (Therapies for Alzheimer's disease sometimes augment the brain's deteriorating cholinergic system.) On the other hand, estrogen is thought to play a role in increasing the production of acetylcholine. Acetylcholine deficiency is considered to be an aetiological factor in dementia. It is a neurotransmitter that is implicated in cognitive functions - hence the numerous estrogen receptors in the brain (Zandi et al., 2002).

According to Wurtman's hypothesis (Wurtman and Wurtman, 1989), carbohydrate foods increase the plasma ratio of tryptophan to large and neutral amino acids (tyrosine, phenylalanine, leucine, isoleucine and valine). Tryptophan is the precursor of the neurotransmitter serotonin which is transformed by the enzyme tryptophan hydroxylase.

There is consistent evidence demonstrating the beneficial effects of glucose on cognitive performance and mood in healthy volunteers such as in reaction time (Owens and Benton, 1994), rapid visual information (Donohoe and Benton, 1999), and for the Stroop effect (Benton et al., 1994). Sugars are the main components

\footnotetext{
${ }^{1}$ Food and Nutrition Department King Abdulazziz University
} Received February 15, 2015, Accepted March18, 2015 
of date fruit, and they are mainly reducing sugars in the form of glucose. The glucose concentration in dates at Tamr stage ranges from $44.3 \%$ to $64.1 \%$ (Ahmed and Ahmed, 1995) and it can be as high as $88 \%$ in some varieties (Shinwari, 1993). Also, Ahmed and Ahmed have reported that the glucose: fructose ratio is of 1.1 in Tamer dates. This classified the date as a low glycaemic index (GI) food as a result of the high content of fructose and fiber (Miller et al., 2003) (The glycaemic index (GI), is a system of classifying food items by glycaemic response)

Because of the many active ingredients present in date fruit, it is difficult to assess a specific psychopharmacological mechanism underlying its effects. Therefore, the aim of the current study was to investigate the possible cognitive or mood effects following the administration of a single dose of $250 \mathrm{ml}$ of the date's drink to healthy volunteers, using several cognitive computerized assessments.

\section{MATERIALS AND METHODS}

There was a blind placebo controlled study. Fifteen participants (nine females, and six males), whose mean age was $29.2( \pm 6.07)$ years. Prior to participation, each volunteer signed an informed consent form and completed a screening questionnaire. All participants reported that they were in good health, and not taking any prescription or over-the-counter medicines. They were not using illicit/social drugs nor any herbal or dietary supplements. However, all participants abstained from smoking and caffeine-containing products on the day of testing.

On each day participants received fruit juices $(250 \mathrm{ml})$ of similar appearance, either date juice or placebo on each occasion (depending in the category to which they were allocated). All drinks were prepared from a larger sample. The date juice was prepared by using a blender machine by adding $1200 \mathrm{~g}$ of date fruit to $2600 \mathrm{ml}$ of water. Thus, one cup of date fruit juice contained approximately $80 \mathrm{~g}$ of date fruit (which is about seven to eight dates). The whole sample was prepared and reserved in individual plastic containers in order to be freeze-dried.

Subjective mood measure: These scales were originally designed for assessing the mood effects of anxiolytics and have been utilized in numerous pharmacological, psychopharmacological, and medical trials (Bond and Lader, 1974). As with other mood visual analogue scales high reliability and validity have been demonstrated (Ahearn, 1997). These scales were combined with the cognitive tasks in the COMPASS framework.
Cognitive measure: General cognitive assessment used a selection of standard computerized cognitive tasks that have previously been shown to be sensitive to dietary applications. The selection of tasks were chosen to provide a comprehensive assessment of performance across the important cognitive domains, that is, attention/concentration, executive function, working memory, secondary memory, spatial memory. Tasks were delivered using the COMPASS framework. Task outcomes have, in all cases, included measures of accuracy and reaction times (with the exception of word recall) with 'yes'/ and 'no' responses being made using simple 'yes' and 'no' buttons. Where appropriate, tasks are given as sets of randomly counterbalanced parallel stimuli and as randomly generated inter-stimulus intervals and stimuli sequences.

Each participant was required to attend two study days, and tests took place at the same time each day. When participants arrived for their first session on the first day, they were briefed on the multiplicity of tests that the trial involved. However, because of the time limitations of this study, it was not possible to offer the participants a training day to allow them to become familiar with the tests and procedures involved. Participants, however, attended preliminaries in a randomized and counterbalanced order. Each active study-day included two identical testing sessions. The first was a pre-dose testing session that established baseline performance for that day, after which participants received their day's treatment. Further testing sessions (post-dose) began at 2 hours following the consumption of the day's treatment. Each testing session included completion of the COMPASS test battery of tasks and questionnaires.

Statistical analysis was performed by using the computer software program (Version 15). Then oneway ANOVA repeated measures were carried out to identify any noteworthy differences between the changes in cognitive performance and mood after treatment and placebo.

\section{RESULTS}

Mean pre-dose row base line scores for both conditions (placebo-treatment) for each mood scale and cognitive task were subjected to one-way ANOVA, prior to analyses of change from baseline data. There were no important differences in baseline performance on any measures. 
Mean pre-dose baseline row scores, and change from baseline scores for both conditions at post-dose time point on subjective mood measures (alert, calm and content) are presented in Table 1.

Table 1. Effect of date fruit juice on subjective mood measures from the Bond-Lader scales

\begin{tabular}{llcccc}
\hline Measure & & Base line & \multicolumn{2}{c}{ change } \\
\hline Alert & & Mean & SD & mean & SD \\
\hline & placebo & 57.78 & 4.24 & -1.84 & 10.22 \\
\hline Content & treatment & 53.63 & 3.85 & $15.77^{* * * *}$ & 7.30 \\
\hline & placebo & 64.41 & 3.64 & -1.65 & 1.87 \\
\hline Calm & treatment & 60.79 & 4.64 & $13.69^{* * * *}$ & 6.80 \\
\hline & placebo & 49.77 & 7.44 & -1.57 & 3.99 \\
\hline
\end{tabular}

$* \mathrm{p}=0.05 ; * * \mathrm{p}=0.01 ; * * * \mathrm{p}=0.005 ; * * * * \mathrm{p}=0.001$ compared to placebo

Bond-Lader visual analogue mood scales

Alert': A one-way (repeated measures) ANOVA revealed a marked improvement on 'alertness' following the administration of $250 \mathrm{ml}$ dose of date fruit juice $(\mathrm{F}(1,14)=18.481, p=0.001)$. The effect size is $56.9 \%$. Therefore, $56.9 \%$ of the variation in scores measuring alertness is accountable by the consumption of date fruit juice.

'Content': An important modulation of the content factor was noted following the administration of $250 \mathrm{ml}$ dose of the date fruit juice $(\mathrm{F}(1,14)=17.072, p=0.001)$. The effect size is $54.9 \%$. Therefore, $54.9 \%$ of the variation in scores measuring alertness is accountable by the consumption of date fruit juice.

'Calm': In comparison to placebo, there was a notable modulation of the calmness factor following the administration of $250 \mathrm{ml}$ dose of the date fruit juice (F $(1,14)=7.041, p=0.019)$.

The effect size is $33.5 \%$. Therefore, $33.5 \%$ of the variation in scores measuring alertness is accountable by the consumption of date fruit juice. The following figures $(1,2$, and 3$)$ show the change from baseline in the three different factors of mood.

Mean pre-dose baseline scores, and change from baseline scores at post-dose point on individual task outcome measures are presented in Table 2.

One-way ANOVA showed that date fruit consumption had an important beneficial effect on the reaction time (msecs) on the numeric working memory task $(\mathrm{F}(1,14)=5.267, p=0.038)$. The size effect size is $27.3 \%$. Therefore, $27.3 \%$ of the variation in scores, measuring numeric working memory reaction time (msecs) is accountable by the consumption of date fruit. Furthermore, trends towards improvement on the percentage of accuracy in the list recognition task ( $\mathrm{F}(1$, 14) $=3.821, p=0.071$ ) were noted. However, there were also trends towards an impairment in performance on the choice reaction time task $(\mathrm{F}(1,14)=3.553$, $p=0.080$ ). No other notable results were observed. 


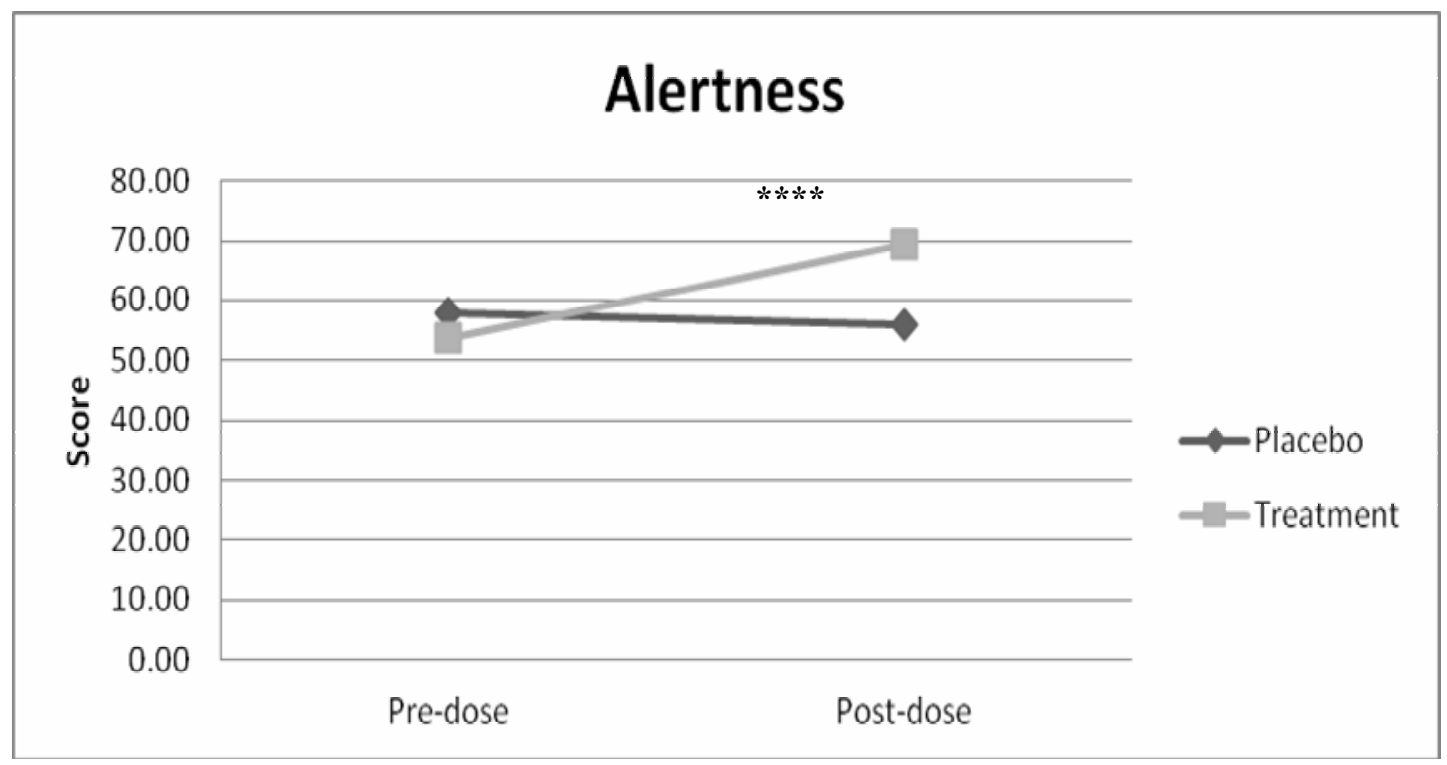

Figure 1. Change from baseline 'alert' mood factor

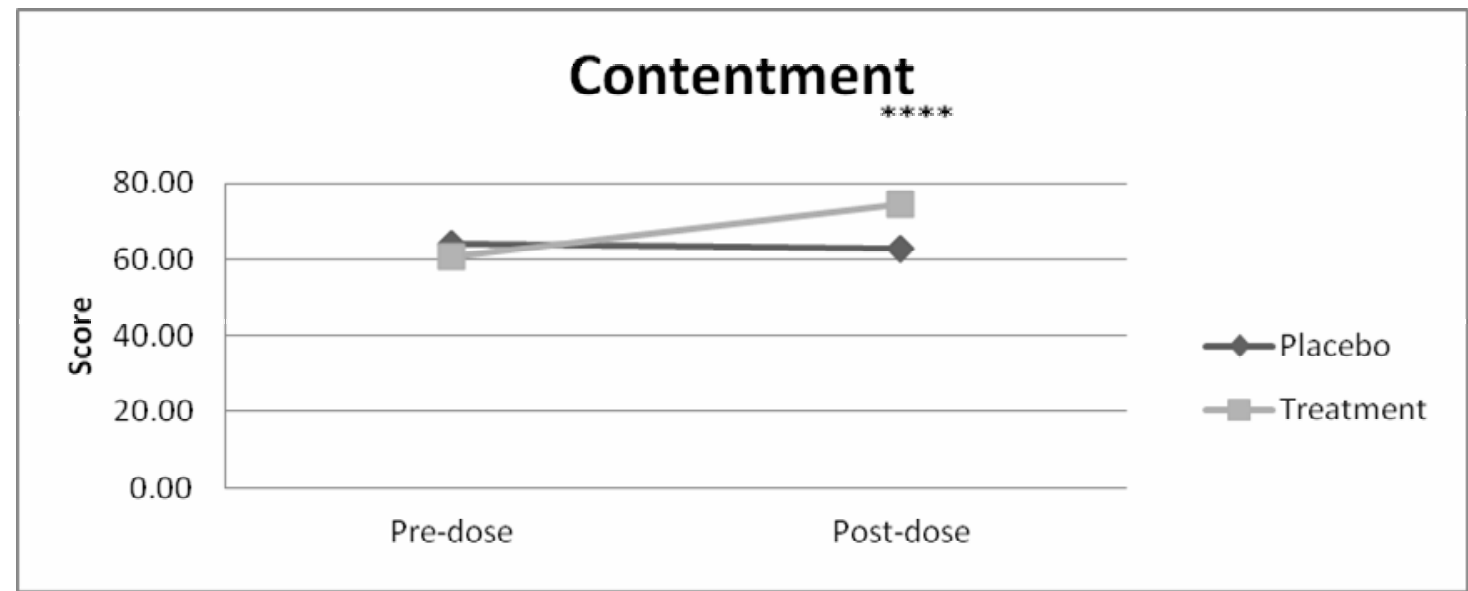

Figure 2. Change from baseline 'content' mood factor

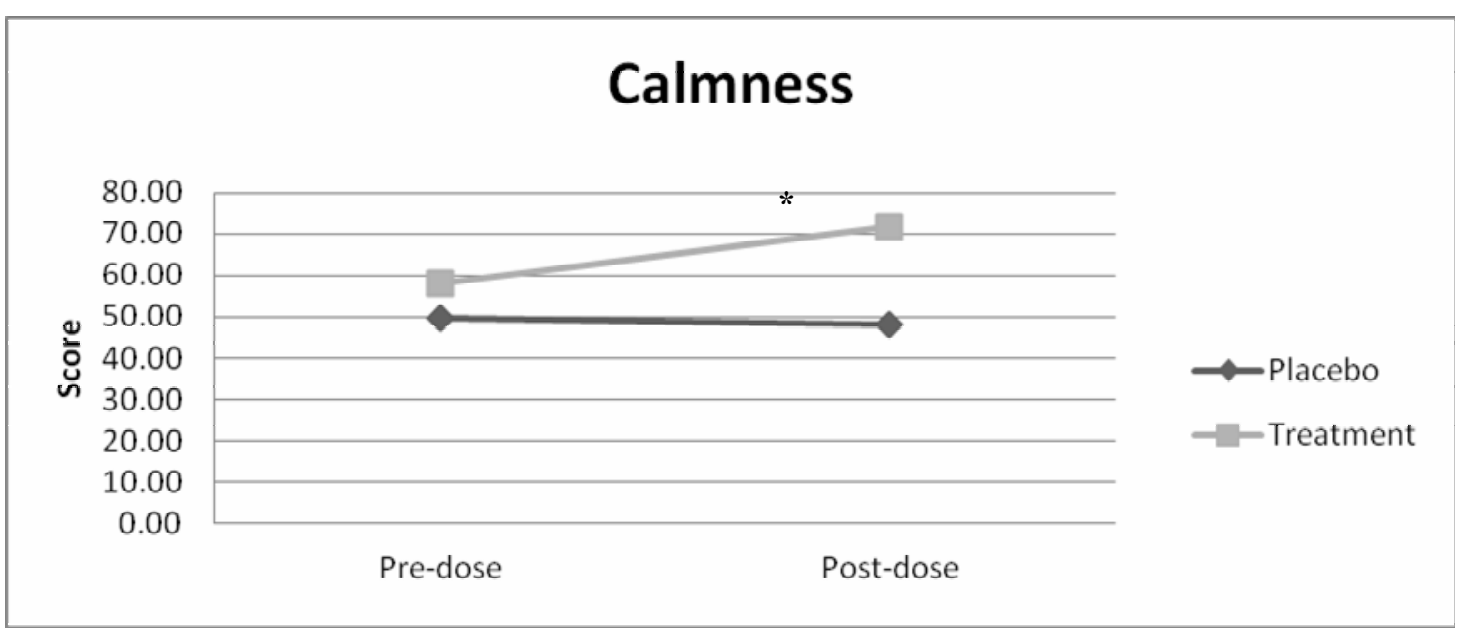

Figure 3. Change from baseline 'calm' mood factor 



\section{DISCUSSION AND CONCLUSION}

These results show that date palm (Phoenix dactylifera) administration can modulate many facets of mood in healthy young adults. Participants were more alert, calmer and more content after two hours of the consumption of the date fruit. The only notable enhancement in cognitive tasks following the administration of date fruit was noticed on the reaction time (msecs) on numeric working memory tasks, which means that the time used (in milliseconds) to respond to these tasks became shorter or, in other words, participants responded faster due to date consumption. Also, there was a trend towards an improvement in the percentage of accuracy (the correct responses) in the task of list recognition. This is an innovative study that investigates the effect of date fruit on mood and cognitive performance. Although more research is needed to identify the most active psychostimulant, positive modulation observed after the administration of date fruit may give some suggestions and indications as to an understanding of the mechanism(s) underlying the effects.

It has been estimated that the total percentage of sugars in $250 \mathrm{ml}$ of date juice is approximately $70.4 \%$; therefore, the important modulation observed in mood in the current study might be attributed to the high content of sugars in date fruit. This means that these results are largely in line with studies investigating the effects of glucose on mood, where sugar-containing drinks have been compared with placebos. Benton et al. (1993) demonstrated that subjects, whose blood glucose remained low, reported a despondent mood compared with subjects whose blood glucose was higher. However, there is a common assumption that any benefits associated with the intake of sugar are short lived, and followed by a rapid fall in blood glucose, a hypoglycaemic rebound, with a resulting lowering of mood. The date fruit is classified as a low glycaemic index (GI) food because of its high content of fructose and fiber. Thus, following the consumption of date fruit one may speculate that the adjustment of mood is long lived and the result of a 2-hour glucose maintenance in blood. However, no blood samples were taken from participants to give extra supportive evidence. In the same regard, dates contain plasma amino acids (tyrosine, phenylalanine, leucine, isoleucine and valine) and tryptophan, and according to the Wurtman hypothesis, Therefore, the enhancement observed in mood in the current study can be attributed to either glucose or a companion of glucose and amino acids in date fruit.

Table 2. Effect of date fruit juice on individual task outcome measures from the COMPASS battery

\begin{tabular}{|c|c|c|c|c|c|}
\hline \multirow[t]{2}{*}{ Measure } & & \multicolumn{2}{|c|}{ Baseline } & \multicolumn{2}{|c|}{ Change } \\
\hline & & Mean & SD & mean & SD \\
\hline \multirow{2}{*}{$\begin{array}{l}\text { Immediate Word Recall } \\
\text { (\%accuracy) }\end{array}$} & Placebo & 6.40 & 1.24 & 3.78 & 13.15 \\
\hline & Treatment & 6.67 & 1.23 & -2.22 & 11.25 \\
\hline \multirow[t]{2}{*}{ Simple Reaction Time } & Placebo & 364.42 & 176.40 & 18.81 & 73.01 \\
\hline & Treatment & 376.96 & 93.10 & -30.88 & 95.80 \\
\hline \multirow{2}{*}{$\begin{array}{l}\text { Choice Reaction Time } \\
\text { (average) }\end{array}$} & Placebo & 475.64 & 68.92 & 22.78 & 98.70 \\
\hline & Treatment & 485.27 & 62.91 & -22.73 & 64.41 \\
\hline \multirow{2}{*}{$\begin{array}{l}\text { Choice Reaction Time (\% } \\
\text { correct) }\end{array}$} & Placebo & 94.93 & 4.83 & -0.13 & 5.68 \\
\hline & Treatment & 96.13 & 3.16 & 0.40 & 3.64 \\
\hline \multirow{2}{*}{$\begin{array}{l}\text { Rapid Vidual Information } \\
\text { average) }\end{array}$} & Placebo & 486.48 & 66.95 & 22.46 & 85.45 \\
\hline & Treatment & 463.20 & 133.23 & 45.09 & 144.83 \\
\hline \multirow{2}{*}{$\begin{array}{l}\text { Rapid Vidual Information } \\
\text { (\%correct) }\end{array}$} & Placebo & 32.86 & 16.29 & 2.65 & 17.08 \\
\hline & Treatment & 33.05 & 21.14 & 1.12 & 26.47 \\
\hline \multirow[t]{2}{*}{ Stroop (msecs) } & Placebo & 1169.40 & 278.80 & -134.53 & 267.89 \\
\hline & Treatment & 1081.80 & 263.81 & -44.53 & 206.91 \\
\hline \multirow[t]{2}{*}{ Stroop (\%accuracy) } & Placebo & 93.33 & 13.80 & 6.67 & 13.80 \\
\hline & Treatment & 94.67 & 17.13 & 4.89 & 15.42 \\
\hline \multirow{2}{*}{$\begin{array}{l}\text { Numeric Working Memory } \\
\text { (msecs) }\end{array}$} & Placebo & 1351.75 & 416.56 & -187.02 & 231.74 \\
\hline & Treatment & 1179.42 & 389.21 & $55.96^{*}$ & 286.13 \\
\hline \multirow{2}{*}{$\begin{array}{l}\text { Numeric Working Memory } \\
\text { (\%accuracy) }\end{array}$} & Placebo & 91.33 & 5.91 & 39.73 & 152.44 \\
\hline & Treatment & 91.04 & 10.75 & 1.82 & 6.68 \\
\hline N-BACK Task (msecs) & Placebo & 893.66 & 612.23 & -89.35 & 614.57 \\
\hline
\end{tabular}




\begin{tabular}{|c|c|c|c|c|c|}
\hline & Treatment & 867.97 & 548.53 & -24.44 & 282.72 \\
\hline \multirow{2}{*}{$\begin{array}{l}\text { N-BACK Task } \\
\text { (\%accuracy) }\end{array}$} & Placebo & 58.82 & 13.80 & 3.55 & 13.90 \\
\hline & Treatment & 66.37 & 20.54 & 6.16 & 17.31 \\
\hline \multirow[t]{2}{*}{ Corsi Block } & Placebo & 5.05 & 0.78 & -0.47 & 1.81 \\
\hline & Treatment & 5.07 & 1.24 & -0.01 & 1.08 \\
\hline \multirow[t]{2}{*}{ List Recognition (msecs) } & Placebo & 1431.67 & 466.22 & 58.07 & 294.67 \\
\hline & Treatment & 1408.67 & 393.35 & 137.47 & 243.96 \\
\hline \multirow{2}{*}{$\begin{array}{l}\text { List Recognition } \\
\text { (\%accuracy) }\end{array}$} & Placebo & 81.78 & 9.91 & -3.33 & 9.84 \\
\hline & Treatment & 78.67 & 9.07 & 2.67 & 9.69 \\
\hline \multirow[t]{2}{*}{ Picture Recognition (msecs) } & Placebo & 1239.13 & 196.14 & 67.13 & 259.54 \\
\hline & Treatment & 1261.40 & 313.95 & 149.00 & 172.45 \\
\hline \multirow{2}{*}{$\begin{array}{l}\text { Picture Recognition } \\
\text { (\%accuracy) }\end{array}$} & Placebo & 80.40 & 9.72 & -4.18 & 16.77 \\
\hline & Treatment & 81.11 & 8.61 & 2.20 & 12.80 \\
\hline \multirow{2}{*}{$\begin{array}{l}\text { Delayed Word Recall } \\
\text { (average) }\end{array}$} & Placebo & 5.27 & 1.33 & 1.78 & 8.90 \\
\hline & Treatment & 5.53 & 1.36 & 5.33 & 10.68 \\
\hline
\end{tabular}

$* \mathrm{p}=0.05 ; * * \mathrm{p}=0.01 ; * * * \mathrm{p}=0.005 ; * * * \mathrm{p}=0.001$ compared with placebo

Moreover, an important association has been reported between mood and iron status in healthy subjects (Fordy and Benton, 1994). Therefore, food supplements rich in iron may have a positive effect on mood. Date fruit can be considered as a practical supplement of iron; thus there may be an association between mood changes and the quantity of iron in date fruit.

In cognitive performance, date fruit had an important effect on the reaction time (msecs) on numeric working memory tasks. Also, there was a trend towards an improvement in the percentage of accuracy in the task of list recognition. These improvements could be associated with the treatment doses. Whole fruit contains many potentially neuroactive constituents (many yet unidentified), but it is not yet possible to meaningfully quantify these psychoactive properties. It is clearly of great interest to identify such active agents. On the broader question of a possible medicinal role for date fruit, it is notable that the results evident here support the hypothesis that date fruit may eventually have a role to play in the enhancement of mood and cognitive performance. Date fruit has wide-ranging potential and it is interesting to speculate that the pharmacological arsenal for mood modulation might be linked to cognitive performance in a larger trial and with different doses. Modifying the doses of date fruit, in keeping with observed beneficial effects, may be relevant especially in elderly people.

Considering the impairment trends observed on the choice reaction time task, an important factor might be caffeine-deprivation. Participants were asked to abstain from caffeine products in the current study as these were thought to affect performance. However, caffeine withdrawal is still an area of much controversy. Some studies have shown that caffeine withdrawal can impair short-term memory performance (James, 1998). Also, impairment of cognitive performance has been interpreted as an effect or effects of caffeine withdrawal in some other studies (Rizzo et al., 1988; Bruce et al., 1991). Therefore, investigating the effect of date fruit on cognitive performance in non-caffeine users may have a different effect.

The current study raises a number of important issues: whether or not an increased dose of date fruit (above the dose used in this trial) may confer additional benefits, and how high the dose should be in order to enhance performance and mood. The issue of chronic effects and, more specifically, the effects of date fruit in cognitive performance also requires elucidation.

The implications of these results are that modulation on mood after the consumption of date fruit may be beneficial in the treatment of mood irritability caused by conditions such as Alzheimer's disease or in menopausal and premenopausal conditions in women. Six to eight tamer dates were used in the study - a similar quantity to that consumed by many Middle Eastern Arabic people at a single sitting. Furthermore, diabetics can be reassured that consumption of dates, in similar quantities to those used in this study, will not result in rapid and large fluctuations in blood sugar (Miller et al., 2003).

\section{REFERENCES}

Ahearn, E. (1997). The use of visual analog scale in mood disorders: A critical review. J Psychiatr Res. 31: 569-579. 
Ahmed, I.and Ahmed, K. (1995).Chemical composition of date varieties as influenced by the stage of ripening. Food Chem. 54: 305-309.

Al-Shahib, W.and Marshall, J. (2003). The fruit of the date palm: its possible use as the best food for the future? Int $\mathbf{J}$ Food Sciences Nutr. 54: 247-259.

Al-Shahib, W.and Marshall, R. (2002).Dietary fibre content of 13 varieties of date palm (Phoenix dactylifera L.). J Food Sci Technol. 37: 719-721.

Al-Showiman, S. (1998). Al Tamr, Getha was saha (Date food and health). Saudi Arabia: Dar Al-KharjiPress.

Ashcraft, M. (2002).Cognition.3rd edn. Pearson Education Prentice-Hall Inc.

Benton, D. and Owens, D. (1993).Is rasid blood glucose associated with the relief of tension? J Psychosom Res .37: 1-13

Benton, D., Owens, D. and Parker, P. (1994). Blood glucose memory and attention.Neuropsychologia. 32: 595-607.

Bond, A, andLader, M. (1974). The use of analogue scales in rating subjective feelings. Br J Psychol 47: 211-218.

Bruce, M. Scott, N. , Shine, P. and Lader, M. (1991). Caffeine withdrawal: A contrast of withdrawal symptoms in normal subjects who have abstained from caffeine for 24 hours for 7 days. J Psychopharmacol. (5): 1291-34.

Donohoe, R. and Benton, D. (1999). Declining blood glucose levels after a cognitively demanding task predict subsequent memory. NutrNeurosci. (2): 413-424.

Doraiswamy, P., Bieber, F., Kaiser, L., Krishnan, K., Reuning.S, and Gulanski, B. (1997). The Alzheimer's Disease Assessment Scale: patterns and predictors of baseline cognitive performance in multicenter Alzheimer's disease trials. Neurology. 48:1511-1517.

Fordy, J.and Benton, D. (1994). Does low iron status influence psychological functioning? J Human NutrDietet. 7: $127-33$.
Haller, J. (2005). Vitamins and brain Function. In HR. Lieberman RB.Kanarek\& C. Prasad (eds.), Nutritional neuroscience. Boca Raton, FL: CRC Press.

Huskisson, E, Maggini, S.andRuf, M. (2007), The influence of micronutrients on cognitive function and performance. $\mathrm{J}$ Int Med Res. 35 (3): 277-289.

James, J. (1998). Acute and chronic effects on performance, mood, headach and sleep.Neuropsychology. 38: 32-41.

Miller, C. ,Dunn, E .and Hashim, I. (2003). The glycaemic index of dates and date \& yoghurt mixed meals. Are dates 'the candy that grows on trees'? Eur J ClinNutr. 57: 427430

Mustafa AI, Hamad AM \& Al-Kahtani MS. (1983) Date varieties for jam production. In Proceedings of the First Symposium on the Date Palm in Saudi Arabia, King Faisal University, Al-Hassa. pp. 496-501.

Owens, D. and Benton, D. (1994).The impact of raising blood glucose on reaction times.Neuropsychobiology. (30):106113.

Rizzo, A., Stamps, L., Lawrence, A. (1988). Effects of caffeine withdrawal on motor performance and heart rate changes. Int J Psychol. (6): 91-94.

Shinwari, M. (1993).Date palm. In Encyclopaedia of food science, Food Technology \& Nutrition, vol. 2, eds. Macrae R, Robinson RK \& Sadler MJ, London: Academic Press. pp. 1300-1305.

Wurtman, R. andWurtman, J. (1989).Carbohydrates and depression.Sci Am. (260): 50-57.

Zandi, P., Carlson, M.,Palssman, B., Welsh Bohmer, K., Mayer, L.,Staffens, D. and Breitner, J. (2002). Hormone replacement therapy and incidence of Alzheimer in older women: the Cache County Study. J Am Med Assoc. 288(17): 2123-2129.

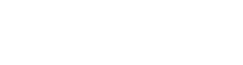

\section{تأثيرشرلب تمر النخل عل الأداء الإرله والمزلجي}

دعاء صالح الطويرقي الإكي

والإدرلكي، فتهف هذه الدرلسة اللتعرف على الآثار

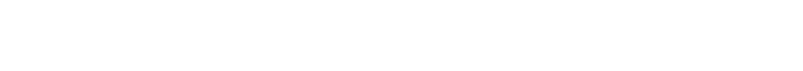

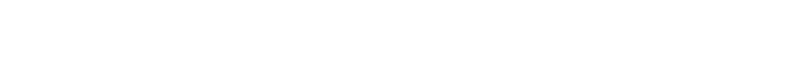

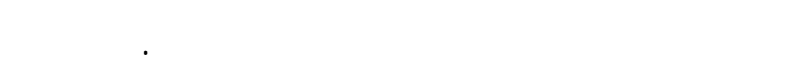

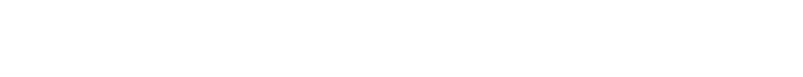
أداء المزاج لدى البالغن. في هذه الدرلسة كان المشاركون
تعتبر ثمرة النخل Phoenix dactylifera عنصرا أسلسيا

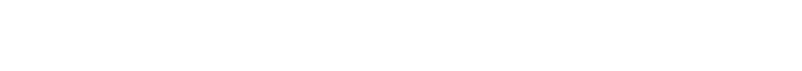

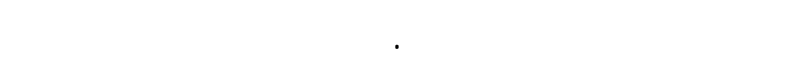

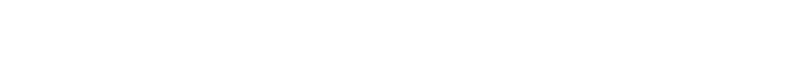

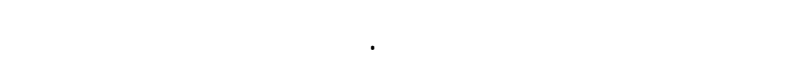

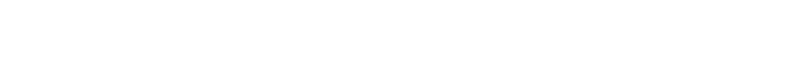


لكثر يقظة وهدوء بعد تناولشرب التمر. لوظظ أهم تعصن الذلكرة. في المهلم الإدرلكية في وقت رد الفعل على عديد من مهلم 